\title{
Automobile Logistics 4.0: Advances Through Digitalization
}

\author{
Marit Hoff-Hoffmeyer-Zlotnik (D), Michael Teucke (D), Stephan Oelker (D), \\ and Michael Freitag
}

\begin{abstract}
In today's buyer's markets, logistical service quality is of great importance, particularly for high-priced products. For many buyers, the automobile is the epitome of a high-priced, individually customized product. Hence, customers expect a high delivery service quality. Distribution logistics provides the link between the manufacturer and the customer and is therefore responsible for providing these services. In automobile logistics, the distribution chain involves several stakeholders, such as manufacturers, transport, and technical services providers, as well as dealers. Seamless coordination between them is crucial. Digitalization is an inevitable means for gaining a high level of transparency among the stakeholders. In addition, it provides technologies for developing effective and tailor-made assistance and control systems that support processes along the distribution chain. In recent years, the BIBA-Bremer Institut für Produktion und Logistik $\mathrm{GmbH}$ has been active in automobile logistics research and has been involved in developing several assistant and control systems that range from relatively simple track and trace systems to highly complex compound control systems. In this paper, we present an overview of the developed systems and provide a vision, how recent and ongoing research improves automobile logistics and how to further potential can be leveraged.
\end{abstract}

M. Hoff-Hoffmeyer-Zlotnik $(\bowtie) \cdot$ M. Teucke $\cdot$ S. Oelker

BIBA - Bremer Institut für Produktion und Logistik GmbH, University of Bremen, Bremen,

Germany

e-mail: hhz@biba.uni-bremen.de; tck@biba.uni-bremen.de; oel@biba.uni-bremen.de

M. Freitag

BIBA - Bremer Institut für Produktion und Logistik GmbH, University of Bremen, Bremen, Germany

Faculty of Production Engineering, University of Bremen, Bremen, Germany

e-mail: fre@biba.uni-bremen.de 


\section{Introduction and Motivation}

\subsection{Research Motivation}

Automobiles constitute high-priced, custom-built consumer goods. Customers expect a high delivery service quality when buying a new car (Klug 2018). The delivery service is an aggregate measure of delivery time, delivery reliability, delivery quality, and delivery flexibility (Pfohl 2010). These features influence customer satisfaction and are thus decisive for the economic success of companies (Seeck 2010). For car manufacturers, it is crucial to deliver vehicles to the customers on time while also meeting quality requirements (Klug 2018; Ambe and Badenhorst-Weiss 2010).

Ensuring a high delivery service quality is the task of distribution logistics. As the link between production and the customer, distribution is responsible for satisfying customer needs by providing customers with the goods they want (Ross 2015).

Overcoming the challenges listed above is particularly difficult when focal companies dominate the order fulfillment process, as it is the case with the car manufacturers in the automotive industry (Scholz-Reiter et al. 2008). Car manufacturers have primarily pursued the goal of optimizing their production processes, whereas the holistic optimization of the whole value chain has been neglected (Hermes 2011; Scholz-Reiter et al. 2008).

As a result, data for distribution planning is often transmitted to the logistics service providers (LSP) incompletely or late. In addition, the actual number of vehicles to be transmitted for transport on the individual routes often deviates significantly from the planned numbers (Holweg and Miemczyk 2002). Therefore, it is not possible to start planning and controlling the activities required for order processing at a sufficiently early stage. Transport planning can usually only be carried out after the end-of-line area when the vehicles are handed over to vehicle logistics. As a result, optimization of the transports is only insufficiently possible.

A further complication exists if the logistics service providers commissioned with distribution are inadequately connected to the manufacturers' information technology (IT) systems (Holweg and Miemczyk 2002). Many vehicle distribution processes are characterized by isolated heterogeneous IT systems, where the companies involved store their data and only forward it in parallel with the material flow (Ruthenbeck et al. 2010). In addition, media discontinuities often occur in the distribution network due to outdated IT systems and the lack of compliance with standards, which generates additional efforts for data entry and thus sources of error (Ruthenbeck et al. 2010). The externalization of logistics services (Gudehus 2010; Klug 2018; Schuh 2013) increases the need for better IT connection and efficient interfaces between the companies involved in distribution (Scholz-Reiter et al. 2009b).

Increasing digitalization in the context of Industry 4.0 offers the potential to improve transparency in supply chains through real-time or near real-time data (Musa et al. 2014; Genc et al. 2014). Industry 4.0 aims to integrate cyber-physical 
systems (CPS) in conjunction with the application of the Internet of Things in production and logistics in order to increase competitiveness (Kagermann et al. 2013). Cyber-physical systems, the Internet of Things, and Digital Twins (Negri et al. 2017) can achieve data availability and data quality to ensure efficient supply chain management (Monostori 2018). The following sub-section provides an overview of the research contribution and the structure of the chapter.

\subsection{Research Contribution}

In recent years, the BIBA-Bremer Institut für Produktion und Logistik GmbH, a member of the Bremen Research Cluster for Dynamics in Logistics (LogDynamics 2021), has done extensive research on increasing information transparency at transshipment points and across the distribution chain, using technologies related to Industry 4.0. In addition, the research includes the development of assistance and control systems that use similar technologies and improve planning and control along the vehicle distribution chain. BIBA's research work addressing the challenges of vehicle distribution was application-driven, meaning it was carried out from the perspective of how Industry 4.0 related technologies and systems can be applied to the planning, control, and execution of logistic processes. The purpose of this chapter is to provide a summary and an overview of this work, its results achieved so far, and the resulting benefits for vehicle distribution logistics.

This chapter is structured as follows: This first section provides an introduction to the topic. The second section describes the processes of finished vehicle logistics and the related planning and control. The third section describes the available digital technologies that can support transparency in distribution processes as well as their planning and control. The fourth section describes several selected assistance and control systems developed by or with the support of BIBA or within LogDynamics and used digital technologies to improve the transparency of vehicle distribution processes. The fifth section points out potential benefits and improvements in vehicle logistics that result from these applications. The final section provides a summary and an outlook on ongoing and future research activities in finished vehicle logistics.

\section{Finished Vehicle Logistics}

\subsection{Tasks of Distribution Logistics}

Distribution logistics provides the link between the manufacturer and the customer (Fig. 1). Functions include planning, managing, executing, and controlling material and information flows between the end of production and handover to the customer (Pfohl 2010). 


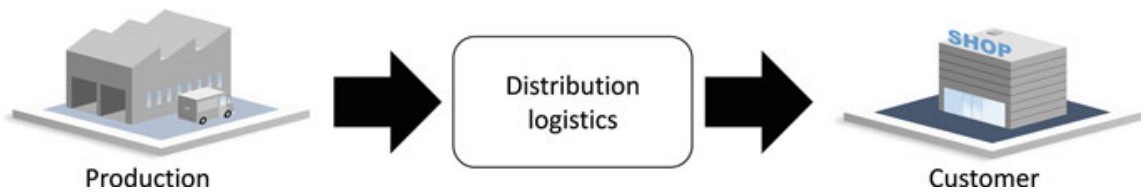

Fig. 1 Distribution logistics (adapted from Filz 1989)

Distribution logistics is divided into order processing, warehousing, and transport (Filz 1989). From the customer's point of view, distribution logistics is vital, as it represents the actual service provision (Hammer and Champy 2003). Within the distribution of finished vehicles, special features are, on the one hand, that specialized load carriers are used and, on the other hand, that the transported goods themselves can move. Therefore, the transport is called roll-on-roll-off (RoRo) transport (Schukraft et al. 2018).

In the automotive sector, distribution logistics begins at the original equipment manufacturer's (OEM) site after the vehicle's production has been completed and the vehicle has successfully passed the quality inspection (Scholz-Reiter et al. 2012 b). There are two alternatives to how the product can reach the customer. On the one hand, in relatively few cases, the finished vehicles are collected from the factory by the customers. This case is not considered further in this article. On the other hand, the finished vehicles are prepared for transport according to their destination and transported to a dealer via a multi-stage multi-modal transport chain. This process makes up a significant fraction of the time from production to reaching the owner; just the crossing from Europe to the USA takes about two weeks, while the production takes only about one day. The distribution process involves the OEM, transport, and technical service providers, and the dealer as stakeholders (Gudehus 2012). The transport process must run as planned because a vehicle is a highly individualized product and is usually customized. Accordingly, another product cannot easily substitute it if it does not arrive at the customer as planned.

Starting from the OEM's site, logistics service providers transport the vehicles from one transshipment point to the next. The logistics service providers have special modes of transport at their disposal and differentiate between surface transport (truck) and en-route transport (especially rail and ship). In long-distance traffic, the transports for several OEMs are usually combined so that vehicles from different manufacturers can be found on the same ship.

Figure 2 illustrates an overview of the distribution network in Europe. An exemplary distribution chain for finished vehicles is a three-stage transport chain. The finished vehicles leave the OEM and are transported from there by train or truck to a transshipment point (pre-carriage). From there, a ship, train, or truck transports the vehicles to a second transshipment point, which is as close as possible to the destination of the vehicles (main-carriage). Afterward, the vehicles are usually transported by truck to the dealer (on-carriage). At each transshipment point, a quality check is carried out. In general, international vehicle distribution mainly 


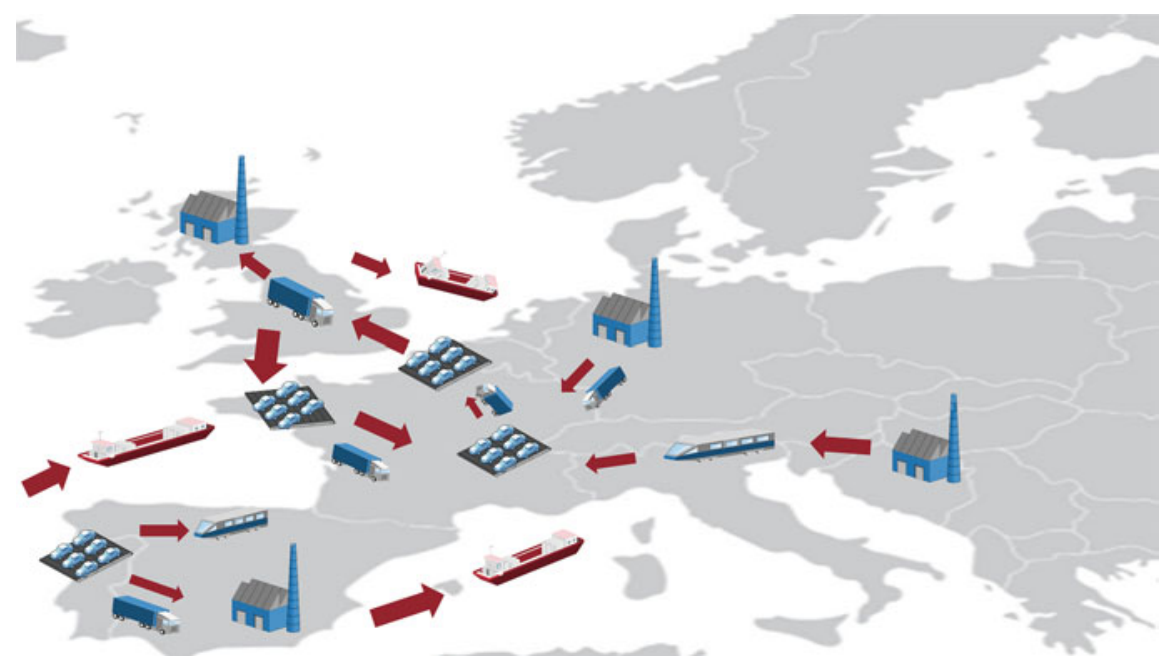

Fig. 2 Exemplary distribution chains for finished vehicle distribution (adapted from Haubrich 2017)

takes place by ship. Within Europe, rail is mainly used, as it is cheaper than a truck (Klug 2018; Herold 2005).

The transshipment points for finished vehicles play a special role in the finished vehicle supply chain. The so-called vehicle compounds can handle several million vehicles per year, load and unload over one thousand ships per year and store up to 100,000 vehicles on site (Klug 2018). In addition, to storing and turning over vehicles, technical services are often offered at the transshipment points. These services, which can be booked at short notice, include, for example, washing and removal of the transport protection film, installation of special equipment and accessories, or technical modifications (Fischer 2004). This means that customer wishes can be implemented relatively late in the process chain. In addition, slight damage to the vehicles can be repaired immediately, and the vehicles do not have to be transported to a repair shop or back to the OEM.

Dealers are the last point in the supply chain before the vehicle is handed over to the customer. The delivery to the dealers is usually made by truck from the last transshipment point (Ruthenbeck et al. 2010). The dealers are in direct contact with the end customer, so they need to know when the vehicles will arrive at their premises. They can inform the customers about the progress and arrange a handover date. The next sub-section describes the processes and challenges for planning and controlling the logistics of finished vehicles. 


\subsection{Planning and Control Within Finished Vehicle Logistics}

Planning and control consider the temporal, quantitative, and, if necessary, spatial aspects of production and logistics processes. Planning makes decisions on anticipated future operations to prepare their best possible execution. For instance, planning identifies alternative process executions, evaluates the alternative options, and selects the best available option. Strategic, tactical, and operational planning correspond to a long, medium, and short-term time planning horizon. Control takes place in parallel with the processes and allows for intervention in case deviations from the plan have occurred in the meantime (Lödding 2011).

Within the distribution of finished vehicles, many different players are involved, and therefore, the planning and control of the entire distribution chain pose a challenge. In terms of day-to-day coordination among the different companies, operational planning and control levels are of particular interest. The process starts at the manufacturers. Based on order information from the dealers, they plan the distribution routes and monitor and coordinate the distribution along the entire distribution chain (Klug 2018). As soon as the vehicles enter the delivery process, the manufacturer is in contact with the logistics service providers to exchange information about transport, service, blockings, confirmations, entry and exit bookings, loss, damage, rework, and technical services (Schenk and Clausen 2020). However, a uniform IT system for standardized information exchange across all companies does not exist (Schenk and Clausen 2020). All parties work with their systems and with different levels of formality, automation, and assistance.

Vehicle compounds are of particular importance within distribution logistics as they serve as intermediate storage facilities, deconsolidation, and consolidation points and offer technical services (Klug 2018). Operational planning and control of a vehicle compound involve, among others, the following tasks: (i) allocation of loading and unloading points to specific modes of transport, (ii) parking space allocation for the vehicles with the aim of short travel distances on the compound, (iii) planning and control of the technical service centers, and (iv) assignment of specific transport orders to the driving personnel (Hoff-Hoffmeyer-Zlotnik et al. 2017; Görges and Freitag 2019b). However, the information that is available to the vehicle compounds beforehand is limited. For example, detailed information, such as the exact number of vehicles, the required technical services, or the forwarding travel date, might be missing. Thus, detailed planning on the level of single vehicles is challenging, and actions often need to be taken spontaneously and in a flexible manner (Haubrich 2017).

Vehicle compounds are located between the manufacturers and dealers (Fig. 3). While manufacturers serve the distribution chain forecast-driven and via push principles, the dealers' goal is to take the finished vehicles based on demand and thus according to the pull principle (Dias et al. 2010). As a result, the vehicle compounds fulfill a buffer function between the automobile manufacturer and the dealer and thus enable a particularly high degree of flexibility within the distribution chain. However, this comes at the cost of an exceptionally high planning and control 


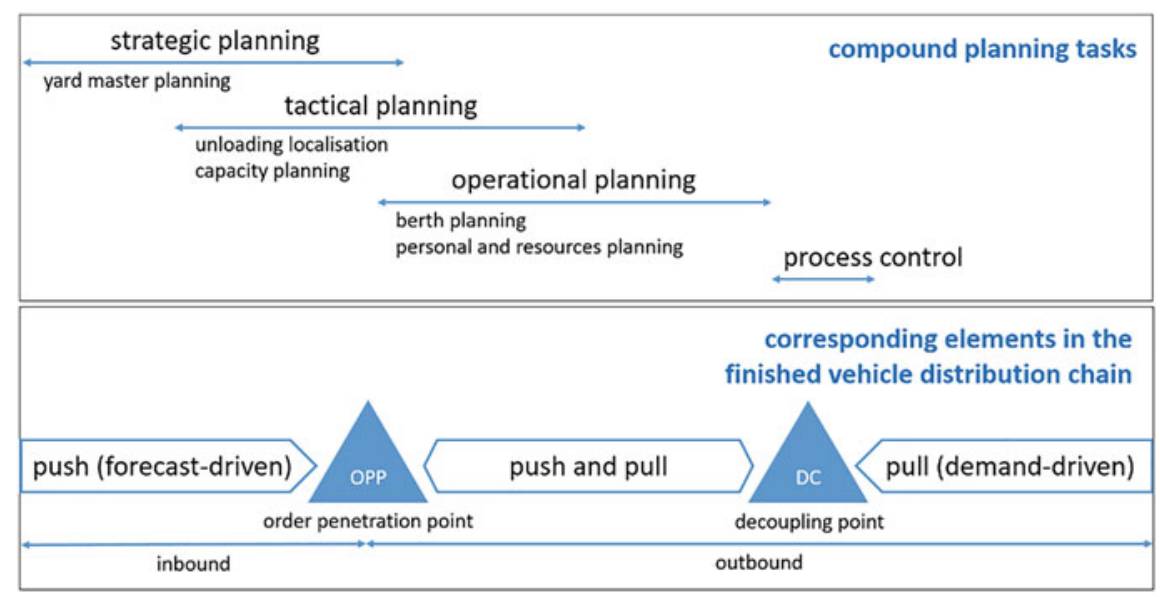

Fig. 3 Planning and control at vehicle compounds (adapted from Görges and Freitag 2019b)

effort for the vehicle compounds (Görges and Freitag 2019a; Görges and Freitag $2019 b$ ). Therefore, the next section describes different technologies for providing information and enabling transparency along the distribution chain.

\section{Technological Basis for Generating Transparency}

In order to obtain transparency about the current status of the process chain, corresponding data is required. This data can, for example, provide valuable information about the current position or condition of the vehicle. From this, it can be derived whether the process is still within the planned state or whether measures need to be taken. Different technologies have been established to collect this data, which will be briefly presented in the following. In addition, the standards for data exchange are also described shortly. An overview of the presented technologies and standards is given in Fig. 4.

\subsection{Automatic Identification Technologies}

Automatic identification systems are technologies for identification, data acquisition, data collection, and data transmission. The focus is on the assignment of two independent objects. As an example, a number is assigned to a vehicle. Automatic identification is understood to mean the automation of data input into a computer or a communication system. This assignment, i.e., the coding, takes place by means 


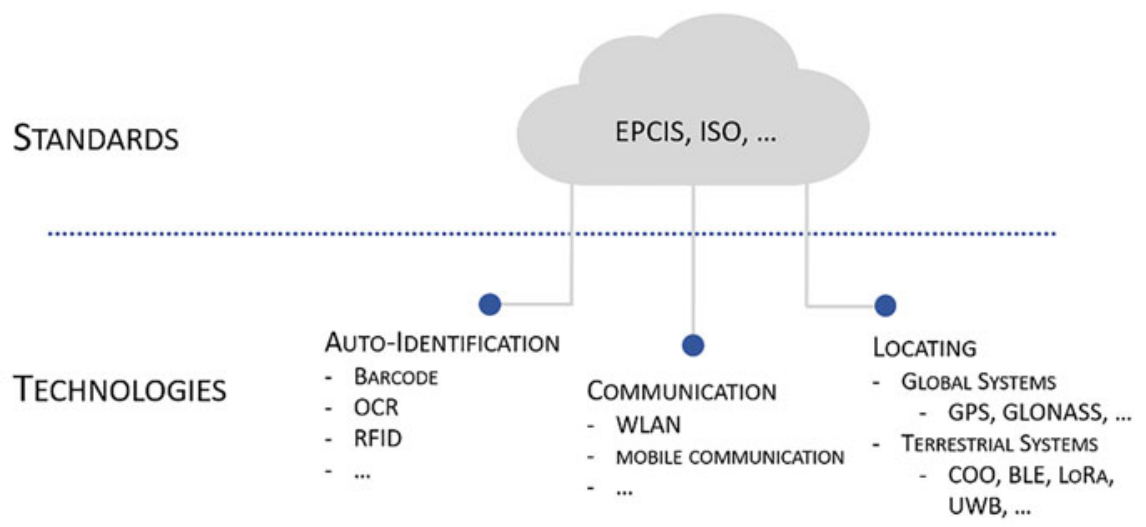

Fig. 4 Overview of technologies and standards that are the basis to gain transparency

of automatic identification. In the following, barcode, OCR, and RFID are briefly introduced, as these technologies are most frequently used in the automotive sector.

\subsubsection{Barcode}

The barcode is a 1D code, and the functional principle is similar to Morse code. Accordingly, in the simplest form, there are thick bars, thin bars and spaces, which are then interpreted into characters accordingly (Schenk 2021).

The advantages of the barcode are low label/direct marking costs, a high degree of standardization, and a high level of integration into the logistics value chain (Jesse and Rosenbaum 2000). Moreover, metal, water, and heat do not influence it. The disadvantages are that a barcode requires a direct line-of-sight, is susceptible to contamination, has low data capacity and density, and is inflexible regarding the subsequent change (Jesse and Rosenbaum 2000). Nevertheless, they have high acceptance in practice.

\subsubsection{Optical Character Recognition}

Optical character recognition (OCR) refers to automated text recognition or automatic character recognition within images. In principle, optical recording, for example, delivers a raster graphic as a result with a camera. Text recognition aims to recognize the characters recorded with the image and transfer them into a different format, e.g., plain text, with which further systems can work. For example, in the automotive sector, the vehicle identification number can be photographed and automatically converted into a machine-readable format (Mori et al. 1992). 


\subsubsection{Radio-Frequency Identification}

Radio-frequency identification (RFID) is the term used for transmitter-receiver systems. By transmitting data using radio waves, RFID enables automatic and contactless identification on the one hand and the location of objects on the other. An RFID system always consists of two components:

- A transponder, which is also called a tag. The tag consists of a coupling element, a transmitting/receiving antenna, and a microchip on which data can be stored. In the automotive sector, for example, the vehicle identification number can be stored on the microchip.

- In addition, there is the reader, which can be permanently installed, e.g., in a gate, or mobile, e.g., a handheld reader (Finkenzeller 2015).

RFID systems can be divided into active and passive systems. The main difference is that in an active system, the tags have their own power supply. This usually increases the range and accuracy. However, these systems require more maintenance and are usually more expensive than passive systems. Passive systems do not have their own power supply. The transponder, therefore, draws the energy it needs from a field generated by the reader. The energy transmission and the data transfer take place completely contactless. The passive systems are usually cheaper, but the range and accuracy are generally lower than an active system (Finkenzeller 2015).

\subsection{Location (Geopositioning) Technologies}

Location finding systems can determine the location of objects in two-dimensional or three-dimensional space. A large variety of systems for automatic location are available, which differ in their geographical scope (or range) and their purpose (Nait-Sidi-Moh et al. 2013).

The location of an object may be computed using different principles. Triangulation, for instance, involves forming triangles to the object from known reference points, establishing a combination of distances and angles. In contrast, multilateration determines the distances between an object and several known reference points (Strang et al. 2008).

Most systems use radiolocation based on the known characteristics of radio waves (e.g., field strength or propagation speed) to encode the necessary data. This includes measurement technologies like time-of-flight, round-trip-times, and received signal strength (RSSI) for multi-lateration and angle-of-arrival (AoA) estimation for triangulation. Another measurement technique is fingerprinting, which involves comparing the RSSI or other properties of a signal with the previously mapped local profile (fingerprint) of that same signal. For local or indoor applications, optical technologies (like visible or infra-red light), magnetic fields, or ultrasound may be used besides radiolocation (Strang et al. 2008). 
The geographical area for which a system offers its location service differs very strongly between global coverage or extended regions to local coverage of a restricted terrain and a single building.

\subsubsection{Global Navigation Satellite Systems}

Global navigation systems provide global or regional positioning data using satellites circling around the earth at known altitudes. Thus, they are also known as global navigation satellite systems (GNSS). The satellites transmit their geospatial position as well as time data by radio. Based on the received time signals of at least four satellites within their line-of-sight, computation devices with built-in receivers can determine their location (longitude, latitude, and altitude/elevation) to precision within a few meters, using the Time Difference of Arrival (TDoA) method (Hofmann-Wellenhof et al. 2008). Current operational GNSS are the American Global Positioning System (GPS), the Russian Global Navigation Satellite System (GLONASS), the Chinese BeiDou Navigation Satellite System (BDS), and the European Galileo system. The Japanese Quasi-Zenith Satellite System (QZSS) currently enhances the accuracy of the GPS and plans to provide satellite navigation independent of GPS in the future (Kaplan and Hegarty 2017). The Indian Regional Navigation Satellite System (IRNSS) currently offers regional location services and plans to expand to a global version in the long term. These systems can be used to determine and track the location of vehicles during medium or long-distance transports.

\subsubsection{Terrestrial Systems}

There are also terrestrial systems that allow locating an object within a larger area. One example for the latter is the tracking of mobile phones through the location areas of a telecommunications network using the cell-of-origin (COO) method, where the location at a certain time is approximated by the circular area covered by the cell the device is connected to (Strang et al. 2008). In addition, the extensive installation of wireless local area networks (WLAN or Wi-Fi) and hotspots allows a more exact location based on the identification of previously mapped WLANs and hotspots.

Local positioning systems do not provide global coverage but have a limited range. Therefore, they can be used for locating a vehicle on a compound. Indoor positioning systems are optimized for use within individual buildings, where satellite signals cannot be received. They typically offer centimeter accuracy. Some provide orientation information, in addition to location information. Such systems are often used in automobile production shops, e.g., at the end-of-line. For these latter purposes, a variety of systems and technologies are in use. A well-known technology is Bluetooth Low Energy (BLE), using beacons to emit signals. The position can be computed via trilateration or via fingerprinting. Other systems 
are based on Long Range Wide Area Network (LoRa), Industrial, Scientific and Medical (ISM) Band, or Ultra-Wide Band (UWB) (Zekavat and Buehrer 2019).

\subsection{Communication Technologies}

In addition to collecting information and locating the position of vehicles, the forwarding of information is of particular importance. Accordingly, common communication technologies are presented below without any claim to completeness.

\subsubsection{Wireless Local Area Network}

Wireless Local Area Network (WLAN) refers to a local radio network. It is often also called Wi-Fi. In principle, one access point is sufficient for such a radio network. However, in order to cover larger areas, several access points are used. The network is operated in the free frequency band at $2.4 \mathrm{GHz}$. With commercially available transmitters, ranges of 30 to 100 meters can be achieved in the free field. With special omnidirectional antennas, 100 to 300 meters can be covered. If the WLAN is connected to the internet, data can be exchanged worldwide (Rech 2012).

\subsubsection{Mobile Communications}

Mobile radio is understood to mean the standards and regulations with which communication takes place. There are different technologies and systems for mobile communication. For example, the fifth-generation $(5 \mathrm{G})$ is currently available in Germany and enables transmission rates of up to $10 \mathrm{Gbit} / \mathrm{s}$. The cellular network works similarly to a WLAN network (Pham et al. 2020). For example, the devices connect to an access point, and the information is transported from there to the desired recipient.

Another form of mobile communication is satellite communication. The access points are satellites in orbit. However, this type of communication is usually associated with high costs.

\subsection{Technologies and Standards for Data Exchange}

The Electronic Product Code Information Services (EPCIS) industry standard, which has been developed by the international non-profit organization GS1, aims to provide fine-grained data about objects, such as their position and status at a certain time, within a certain context, across companies in value-added networks 
(GS1 EPCglobal 2016; Werthmann et al. 2016). Its primary function is to allow tracking and tracing of objects based on historical and current event data (Tröger 2014).

Event data describes the completion of a specific business process step acting upon one or several objects (GS1 EPCglobal 2016). It includes data about the identity of the objects related to a visibility event (what), the location of the event (where), the time and date of the event (when), and the reason or business context (why) of the event. The event data may be generated by automatic identification or localization of objects, using the already described technologies, or directly in software systems such as enterprise resource planning (ERP) systems.

Individual objects are referenced at the instance level by a globally unique Electronic Product Code (EPC) identifier, taking a Uniform Resource Identifier (URI). Examples are the Serial Shipping Container Code (SSCC) or the Global Individual Asset Identifier (GIAI). The standard provides two location types, read points and business locations, to describe the location where an event occurred. Both use a globally unique Global Location Number (GLN). To describe the event time, i.e., the date and time at which the event took place, the standard uses either local time and time zone or a globally unique UTC (Universal Time Coordinated) timestamp. The business context includes the business step in which the event occurs, the business state of the object(s) after the event, shipping and receiving parties, links to relevant business transaction documents, and instance or lot level master data.

Besides the EPCIS industry standard, another important family of independent branch standards that can be used for the global identification of logistic objects has been created by the ISO/IEC Joint Technical Committee 1 (JTC 1). JTC 1 is a joint subcommittee of the International Organization for Standardization (ISO) and the International Electrotechnical Commission (IEC). These standards fall into three categories: A first category specifies systematic numbers for identifying objects. One example is the standard ISO/IEC 15459, which describes a globally unique identification number for identifying logistic units, the so-called Unique Transport Unit Identifier (synonymously referred to as License Plate), to identify a transport unit. The identifier consists of three components: an Issuing Agency Code (IAC), which specifies the encoding of the license plate, a Company Identification Number (CIN), which is issued by certified issuing agencies, and an individual serial number. In sum, these are encoded in a maximum of 35 ciphers or capital letters (ISO 2014). A second category includes standards for encoding data on data carriers, which can be attached to logistic units, e.g., barcodes or RFID transponders. Examples are Code 128, a set of symbols for high-density linear barcodes defined in ISO/IEC 15417:2007 (ISO 2007), and ISO/IEC 18000-63, which defines a set of parameters for air interface communications with RFID transponders at $860 \mathrm{MHz}$ to $960 \mathrm{MHz}$ (ISO 2015). A third category describes standards for the exchange of data between IT applications across company boundaries. These include United Nations/Electronic Data Interchange for Administration, Commerce and Transport (UN/EDIFACT) and Extensible Markup Language (XML). UN/EDIFACT is a still widely used international standard for electronic data interchange (EDI), which pro- 
vides a set of syntax rules to structure data, an interactive exchange protocol as well as standard messages for multi-country and multi-industry exchange (Kischporski 2017). XML is a mark-up language for encoding documents in a human-readable and machine-readable format.

In sum, these standards allow a comprehensive encoding of data on logistic objects, like finished vehicles, during the distribution process. Like UN/EDIFACT, some standards are dated and, while still widely used, in the process of replacement by newer standards.

\section{Developed Assistance and Control Systems}

In order to derive benefits from the technologies presented in sect. 3, the recorded data can be processed further and integrated into assistance and control systems. The following sub-sections give an overview of the possible functionalities and levels of automation of assistance systems. Afterwards, assistance systems and control algorithms for fully automated systems developed at BIBA are presented.

\subsection{Possible Functionalities and Levels of Automation}

Assistance systems can range from a simple, e.g., graphical representation of data, over recommender systems that derive recommendations for specific actions to take up to assistance systems that decide fully autonomously (Power 2002). In the context of the research project "RFID-based Automotive Network" (Werthmann et al. 2014), Werthmann et al. classified assistance systems with respect to finished vehicle logistics into five categories (Werthmann et al. 2013; Werthmann et al. 2016). The categorization ranges from low IT support and complexity of the system to high complexity and IT support (Fig. 5):

1. Level 1: Tracking and Tracing: Tracking and tracing consists of the two terms tracking-knowing where an object is and what its status is-and tracingthe chronological sequence of tracked events. The technology increases the transparency within the supply chain and can prevent time-consuming search activities for specific vehicles. In addition, the track and trace information can be used to estimate the scheduling of subsequent events, such as the delivery date for the customer.

2. Level 2: Reporting: This level comprises the transformation and aggregation of the recorded data into new key figures (key performance indicators-KPI). They can, for instance, be derived from the chronological course of events in the distribution chain and be used for the analysis and optimization of processes. Derived process times for certain work steps are an example of such key figures. 


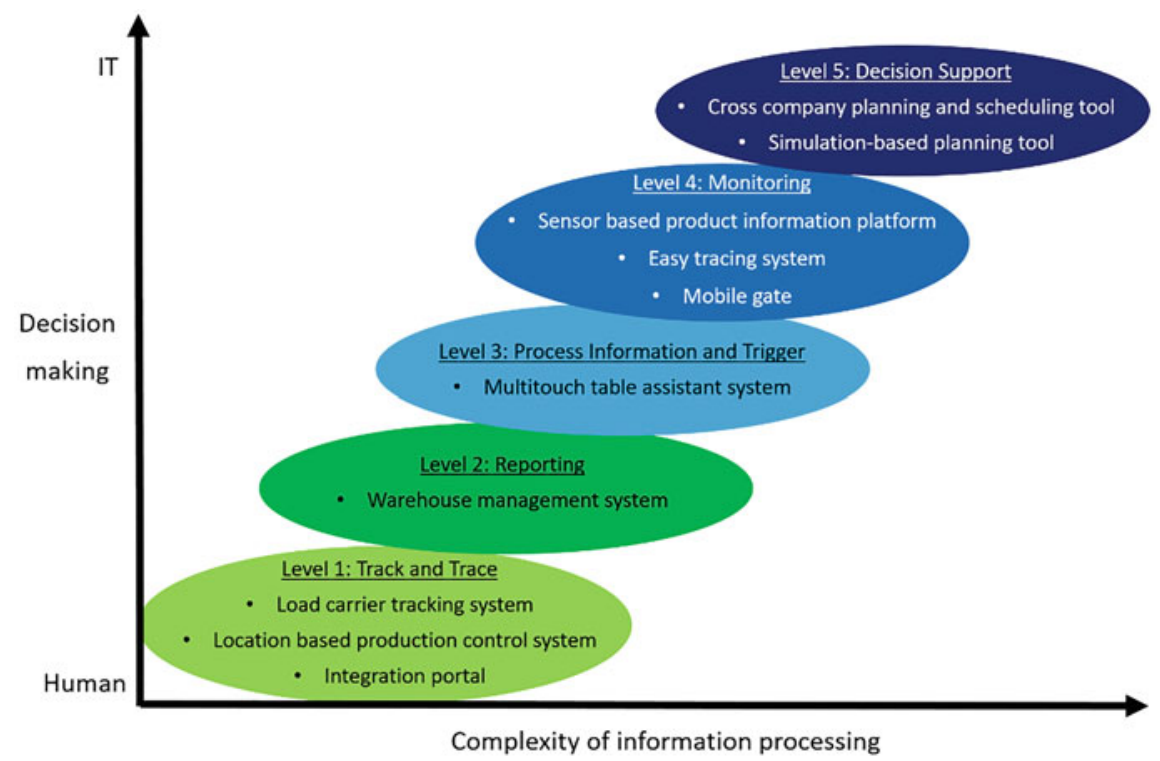

Fig. 5 Categories of functionalities of assistance systems (adapted from Werthmann et al. 2013)

3. Level 3: Process Information and Trigger: This level of an assistance system includes displaying process information for the user and automated triggering of subsequent processes. The triggers must be based on simple rules comparable to those that can be found in e-Kanban systems. By displaying the process information, users can adequately prepare subsequent steps, check the availability of necessary resources, and request them if necessary.

4. Level 4: Monitoring: This level includes monitoring processes and automated warnings when processes deviate from the target process. In the context of finished vehicle logistics, a possible function would be a warning if certain vehicles have not yet been released for loading or in case of a deviation of planned and available resources. The early detection of deviations from the plan creates scope for correcting them and prevents extensive follow-up costs.

5. Level 5: Decision Support: At the level of decision support, systems can weigh up concrete options for the user and present a suitable selection or recommendation. For instance, a decision support system can recommend the sequence in which technical services are applied in the rework of the manufacturer or in service centers of a vehicle compound. Furthermore, events can be triggered automatically, whereby the difference to level 3 is that the decision functions are more complex and can include artificial intelligence. For instance, several alternative options for an action can be evaluated, and the best option can be chosen. In this way, the advantages of mathematical algorithms over manual decisions can be made use of in terms of considered complexity and computation speed. Furthermore, this allows for more flexibility within the distribution chain 
and prevents misdecisions. These latter systems, which no longer require any action on the user's part, are referred to in this article as fully automated systems.

In the following, the systems developed at BIBA and within the LogDynamics network are clustered into assistant systems and fully automated systems. Furthermore, it can be distinguished whether the systems can be applied at individual points in the distribution chain and whether they are designed to be used across several links of the distribution chain.

\subsection{Assistance Systems}

\subsubsection{Assistance Systems at Distribution and Handling Points}

Various assistance systems for automobile logistics have been developed in the past years at BIBA. Most of them are designed for use on vehicle compounds. At this point within the distribution chain, there is a particularly high risk for disruptions (Schenk and Clausen 2020), and thus, assistance systems offer a valuable potential for improvement. In the following, the developed assistance systems are presented according to their level of automation:

Load Carrier Tracking System Load carriers are used at vehicle compounds for loading high and heavy goods that cannot move on their own. The load carriers do not have fixed locations, such as a depot, on the compound. Therefore, search activities can be required to know about the status of resource availability (ScholzReiter et al. 2010a; Lampe 2012). The load carrier tracking system offers a user interface that displays the current locations of the load carriers on a digital map of the compound. In order to track the location, RFID, WLAN, and GPS technology are employed (Scholz-Reiter et al. 2009c; Scholz-Reiter et al. 2010b). The load carriers are equipped with RFID tags, and the tug masters that transport the load carriers are equipped with an RFID reader and a GPS receiver. When a load carrier is parked, the tug master sends its GPS position and the ID of the transported load carrier via WLAN to a database. From there, the user interface obtains the data to display the load carriers on the map. The users can apply filter functions to search for specific load carriers. In addition, the system offers possibilities to support maintenance and inventory processes and billing processes as the load carriers are owned by different players that receive compensation when their carrier is in use (Scholz-Reiter et al. 2010a; Scholz-Reiter et al. 2009a). The system by itself is a tracking system and offers potential for higher levels of assistance.

Passive Real-Time Locating System This location system is based on the Mojix system, which is a terrestrial system for both indoor and outdoor use and uses passive RFID transponders for localization. It can be deployed in technical rework processes at the manufacturer or in technical service centers on vehicle compounds. 
A tracking function informs the worker in which zone (e.g., at which technical station) a vehicle is located or how busy the stations are. On the one hand, the workers save time finding a particular vehicle. On the other hand, the increase in transparency on the utilization of the technical stations allows to improve the overall capacity utilization (Werthmann et al. 2016). The overview on capacity utilization is particularly suitable for process steps that can be freely arranged regarding their sequence. A possible strategy, in this case, is always to choose that process step next for which technical stations offer the shortest waiting time. A simulation study shows that by doing so, the inventories at the stations, the throughput times, and the latter's predictability are reduced compared to the case in which the process steps keep a fixed order. The extent of this effect depends on the average utilization of the stations. The higher the utilization rate, the greater the advantage of the location system (Werthmann et al. 2012). The passive real-time location system corresponds to a level-1-assistance system. In perspective, the transparency provided by the location function can be combined with an automated control system, which detects delays at an early stage and adjusts subsequent processes accordingly (Scholz-Reiter et al. 2012b).

Warehouse Management System This software system can manage warehouses and technical services on a vehicle compound and control the movements of the vehicles on the compound. It allows tracking and tracing functions so that the vehicles' current location, status, and history are available. Furthermore, the system determines process times in order to improve future processes on the vehicle compound and thus offers reporting functions. Therefore, the system is a level-2assistance system (Werthmann et al. 2013; Werthmann et al. 2016). The input to the system can be realized via interfaces to the "Mobile Gate" and "easy Tracing System" which are both presented below.

Mobile Gate The Mobile Gate is a gate equipped with RFID technology to identify passing vehicles (Werthmann et al. 2016). It can be set up at changing positions on a compound. This flexibility is particularly advantageous for loading or unloading ships, as they can dock in different areas. The system requires vehicles to be equipped with RFID tags. The gate then identifies them as they pass through and verifies that the vehicle is being unloaded at the correct port or loaded onto the correct ship. The gate can also generate EPCIS events stored in a higherlevel information system (InfoBroker, see sub-sect. 4.2.2). In addition, the next destination of the vehicle on the compound is shown to the driver. By showing this information, the next process step, the driving process, is triggered (Werthmann et al. 2013). The system is thus a level-4-assistance system.

Easy Tracing System The easy Tracing System (eTS) is a wearable computing system used by the drivers on a vehicle compound. It consists of (i) a sensor box with an RFID reader, a Bluetooth module and a microcontroller, (ii) a mobile phone with GPS, Wi-Fi, a GPRS module, and a touch screen, (iii) a proximity sensor, (iv) an RFID antenna, and (v) batteries for energy supply (Fig. 6; Bleisteiner et al. 2014; Mrugala et al. 2008). Via the mobile phone screen, a driving order and 


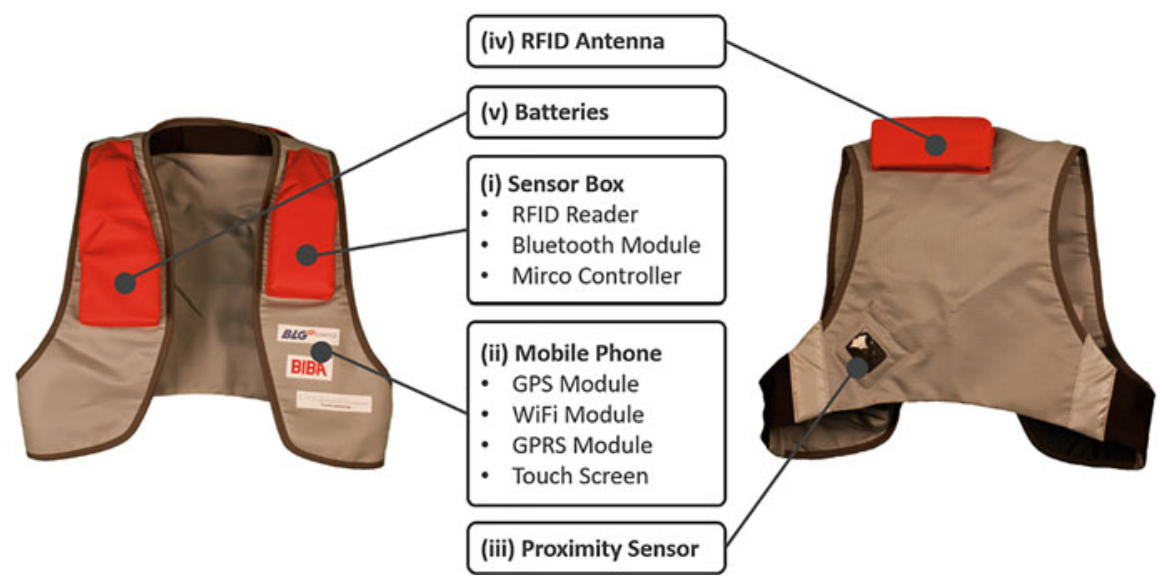

Fig. 6 Easy Tracing System

the corresponding vehicle identification number (VIN), origin, and destination are displayed to the driver. As soon as the driver sits down in the vehicle, the proximity sensor is activated, and the vehicle is identified via the RFID components. Next, it is checked whether it is the correct vehicle. When the driver leaves the vehicle, the geo-position is determined, and it is checked whether it corresponds to the correct destination. The position is then transmitted to a database via Wi-Fi (Werthmann et al. 2016). With the trigger and monitoring functions, the eTS is a level-4-assistance system (Werthmann et al. 2013).

Multi-Touch Table Assistance System This assistance system, developed by Hoff-Hoffmeyer-Zlotnik et al. (2020a), displays the current situation of a vehicle compound on a multi-touch table. It is meant to be used by planners of the compound, and the display shows a map of the compound, which indicates the level of occupancy for all parking areas. In additional information boxes, it displays the occupancy of the quays and tracks and shows status reports of current processes. Furthermore, the users can filter for vehicles assigned to certain processes, such as loading or unloading processes. These vehicles get highlighted at their position on the compound. Several planners can operate the multi-touch table at the same time. This assistance system is a level-3-assistance system due to displaying the process information.

Simulation-Based Planning Tool The planning tool is based on the same multitouch table as described in the previous paragraph. In this setting, the vehicle compound planners can define various medium-term planning scenarios via the multi-touch table. An integrated simulation environment evaluates those in return (Hoff-Hoffmeyer-Zlotnik et al. 2017). Parameters that can be evaluated are order volume, personnel and area planning for the next few weeks to months. The tool presents the results to the planners in graphical form. The planners can retrieve the 
specific results for different points in time via a slide controller (Hoff-HoffmeyerZlotnik et al. 2020a). As the planning tool has complex simulation software and the simulation of the scenarios goes beyond human planning capabilities, it can be seen as a Decision Support System on level 5.

\subsubsection{Assistance Systems for Use Across the Distribution Chain}

Cross-Company Planning and Scheduling Tool The cross-company planning and scheduling tool is a software that aims at improving coordination between compound service providers, technical service providers, and transport service providers (Scholz-Reiter et al. 2009d; Scholz-Reiter and Meinecke 2010). It involves two parts: transportation planning and order sequence planning. Based on the input of the dealer's orders, the tool proposes truck tours. For the proposition of the tours, the tool takes the transport duration, the transportation capacity, the remaining transit time, and the place of delivery into account. The transport service providers receive the suggestions, and they can revise them if necessary. The final formation is forwarded back to the planning and scheduling tool. Subsequently, it proposes a processing sequence for the technical service centers. The sequence is planned via backward scheduling, and the aim is to ensure that the vehicles of the same tour leave the technical service center at the same time. This also allows to lower the size of the dispatching area, the trucks' waiting time, and the duration of the loading processes. The technical service centers receive the proposals and can edit them in case needed. This completes the planning process. As such, the cross-company planning and scheduling tool is a level-5-assistance system. A simulation study shows an improvement of all considered key factors compared to the situation where the tool is not used. The tool lowers the average utilization of disposition area and increases the average load factor, the average on time delivery, the average number of carrying truck tours, and the average number of transported vehicles (ScholzReiter and Meinecke 2011).

InfoBroker The InfoBroker is a system that allows for the cross-company exchange of event data in a standardized form. The event data are, for instance, RFID-generated events along the distribution chain. The underlying standard is EPCIS. The event data gives information on which object was identified at which time at what place for what reason (Werthmann et al. 2016). The system allows to integrate local InfoBroker instances into networks. At the same time, an important feature is a security system that prevents unauthorized access to sensitive data. The companies are categorized according to their role, e.g., manufacturer, logistic service provider, or dealer. Depending on their role, they can receive certain event data and are in charge of supplying certain event data (Brandwein et al. 2013). By regulating the exchange of information based on the company's role, it is ensured that companies only receive information that they are authorized for.

Moreover, the data exchange is limited to information relevant for decisionmaking. Within the companies' IT structure, the information of the InfoBroker can 
be forwarded to assistance systems that further process the data according to the companies' needs (Werthmann et al. 2013). Therefore, the InfoBroker is not an assistance system by itself but can act as a valuable basis for such systems.

Integration Portal The integration portal is a track and trace system that spans across the entire distribution chain and is based on the InfoBroker described in the previous paragraph (Werthmann et al. 2013). Filter functions allow for requesting status information to vehicles, transports, processes, and installed parts. The corresponding vehicles are displayed on a map.

Sensor-Based Product Information Platform This platform allows monitoring the status and logistical quality of products and product components within supply and distribution chains. The platform integrates geolocation, mobile sensors, and telecommunication technologies to record the geolocation of transports as well as quality-relevant environmental influences on the products, e.g., humidity and temperature. Cloud-based digital services analyze the collected sensor data and issue warnings in case of undesirable events, like quality impairments or delivery delays (Teucke et al. 2018; Servos et al. 2020). To facilitate exchange of quality related event-based data across company boundaries, expressions for the exchange of sensor and quality data have been added to the EPCIS standard. The platform is a level-4-assistance system.

\subsection{Control Algorithms for Fully Automated Systems}

\subsubsection{Distinguishing Features}

Several control algorithms have been developed and evaluated in the past years at BIBA that are the basis for control systems on vehicle compounds. These control algorithms use complex decision rules to make fully autonomous decisions about ongoing processes. The objectives of the algorithms are the allocation of parking spaces, the processing order within technical service centers, and the allocation of driving and transport orders to drivers and shuttles. The approaches follow decentralized, centralized, or hybrid control paradigms. Decentralized approaches have the advantage of being able to make use of swarm intelligence. That means they can achieve good system behavior via simple decision rules evaluated within each logistic object (Hongler et al. 2010). Centralized methods can either follow simple rules, such as FIFO. In those cases, they are believed to be outperformed by decentralized approaches. On the other hand, centralized approaches allow for the implementation of complex optimization problems and thus for optimal solutions (Hongler et al. 2010). Hybrid approaches strive to combine the advantages of both. 


\subsubsection{Control Algorithms at Distribution and Handling Points}

Agent-Based Assignment System for Parking Spaces The approach for agentbased assignment of parking spaces on a vehicle compound is a decentrally organized negotiation mechanism. The negotiation happens between the logistic objects, i.e., the vehicles and the parking spaces. The goal of the vehicles is to find the parking space with the shortest possible total travel time to the parking space and from there to the subsequent destination. The goal of the parking spaces is the highest possible occupation. The system can be implemented using RFID, GPS, and IC technologies where the components are to be combined similarly to the easy tracing system described in sub-sect. 4.2 (Böse 2012). A simulation study compares the agent-based assignment mechanism to a central control approach in which the vehicles are assigned to a parking space according to fixed priority rules whereby the priority is not necessarily linked to the length of the travel distances. Using the agent-based negotiation approach, the travel times per vehicle decreased by 26 seconds. In sum, this results in a time saving of 112 working days per year for the compound (Böse and Windt 2007; Böse et al. 2008).

Hybrid Control System for Parking Space Allocation The hybrid control system is an extension of the agent-based approach described above. The hybrid control combines two modules: on the one hand, a module for the agent-based, decentralized parking space allocation, and on the other hand, a module for centralized control of parking space allocation that acts according to priority rules (ScholzReiter et al. 2011). The advantage of the decentralized control module is short travel times. The advantage of the centralized control module is a higher degree of sorting within the parking areas enabling shorter delivery times for subsequent processes. A switching unit that activates the two control modules depending on the situation on the compound aims to combine the advantages of both approaches. A simulation study shows that the hybrid control actually achieves similarly low values for the vehicles' travel times as the decentralized module. In terms of sorting, the hybrid control system achieves values between centralized and decentralized control modules but closer to that of centralized control (Scholz-Reiter et al. 2012a).

Autonomous Control Methods for Process Control Simulation studies investigate the throughput of vehicles through a vehicle compound and compare it for different autonomous control methods (Windt et al. 2010; Becker and Windt 2011). The studies view two processes on the compound: the selection of a parking space (storage process) and the subsequent optional passage through a technical service center (manufacturing process). Four variants of the scenario are set up, and control algorithms from the domain of autonomous control, self-control, multi-agent-based methods, smart systems, and decentralized control are used. These are compared against two benchmark methods. The standard benchmark method provides a fixed order of priorities regarding the selection of parking spaces, whereby the priority differs for vehicles with and without options for technical services. The technical service stations are visited in a fixed order. As a second benchmark scenario, a random method is implemented. Parking spaces and the order in which the 
vehicles pass through the technical service center are randomly selected according to a uniform distribution. The key performance indicators are average time to parking and average parking utilization (storage process) as well as average total treatment time of a vehicle and average due date reliability (manufacturing process). The simulation studies show that the autonomous methods can outperform the benchmark methods but that none of the autonomous methods dominates all other methods overall key figures and scenarios.

\section{Combined Optimal Control System for Order Assignment and Shuttle Routing}

The combined optimal control system for order assignment and shuttle routing is designed for the utilization on a vehicle compound where shuttles are operating to transport handling employees to their subsequent order. A control algorithm assigns driving orders to handle employees and transport orders to shuttles. Furthermore, it coordinates the routing of the shuttle buses. The control algorithm is based on a central control approach that acts via combined optimization. The aim is to achieve the fastest possible processing of all driving orders. The technical implementation is based on a server and smartphones with GPS positioning, an indoor positioning system and WLAN. The server hosts the control algorithm and communicates with the smartphones via WLAN. An app informs the handling employees and shuttle drivers about their next orders. Furthermore, a GPS module on smartphones locates the vehicles when they are parked at their destination. A geofencing system is employed to check whether the correct destination has been reached. If not, the handling employee is informed about the mismatch (Hoff-Hoffmeyer-Zlotnik et al. 2020a). Inside parking racks, where GPS positioning does not work due to the metallic surroundings, a Wi-Fi Round Trip Time-based indoor positioning system is set up (Jathe et al. 2019). Overall, two routing options are available for routing the shuttles: branch-and-bound routing and FIFO routing. The variants differ in terms of waiting times for the shuttles and travel time in the shuttles. However, both offer similar efficiency for processing transfer orders (Hoff-Hoffmeyer-Zlotnik et al. 2020b). Current research works on extending the control algorithm by artificial intelligence modules. The aim is that a combination of critic and actor neural networks make suitable initial guesses for the solution of the optimization problem such that computation time can be saved.

Compound Control System The compound control system is based on the combined optimal control system for order assignment and shuttle routing described above and is currently under development at BIBA. The aim is to extend the system to make it usable for driving orders that start or end within deep-sea ships or enclosed train wagons. Within these modes of transportation, usual Wi-Fi coverage and GPS signal are not available due to the metallic surrounding. The research aims to develop a system that allows for data transfer into and out of the ships and trains such that status reports and new orders can be transmitted. The aimedfor technology is ad-hoc mesh networks based on LoRa Lite technology that spans between the drivers and shuttle drivers within the ship/train. At least one driver or shuttle driver that is in contact with the Wi-Fi network on the compound must always be included to connect the mesh network to the main system. Moreover, two 
mobile applications are under development in this project: Firstly, an application that integrates the stevedores into the compound control systems and allows them to share the stowage plan with the system and request specific vehicles in real-time during the process of loading. Secondly, a mobile application that integrates special cases into the compound control system.

The following section provides BIBA's vision of a transparent finished vehicle distribution chain under adaptive planning and control. The section describes how the presented assistance and control systems contribute to this vision and gives a retrospective on BIBA's research contribution in this field.

\section{Towards Automobile Logistics 4.0}

The vision developed during BIBA's research activities in vehicle distribution processes emphasizes two main points: (1) full transparency of the vehicle distribution chain and (2) fully adaptive planning and control of the vehicle distribution chain. After describing both, the section will present a retrospective on the general trajectory of BIBA's research and future prospects.

\subsection{Vision 1: Fully Transparent Vehicle Distribution Chain}

Digital, Industry 4.0-related technologies can increase transparency for the various processes along the vehicle distribution chain. BIBA's vision of a fully transparent finished vehicle distribution chain that integrates the described technologies, systems, and solutions and makes use of them in a comprehensive manner is shown in Fig. 7: Auto-identification systems based on technologies like RFID or barcode can identify each vehicle at each station in a timely manner. Individually adapted location systems using either satellite-based or terrestrial technologies can determine the vehicles' current locations, either during a long-distance transport or within a limited area, like a vehicle compound or a production shop. These systems can transfer their data automatically to databases that allow data storage of the vehicles during each process step. Standardized information transfer mechanisms, like EPCIS and the InfoBroker, enable efficient data transfer across company boundaries. As a result, more, better, and timelier information is available for every operation.

This transparency gain results in processes that are more efficient and less wasteful. For example, a local information system, like the Easy Tracing System, can immediately give a warning signal when a driver tries to park a vehicle at a wrong (unauthorized) parking area on a vehicle compound. Moreover, the system stores the chosen parking position. Consequently, the frequent searches for vehicles on compounds that require high workforce capacities and thus cause high costs can be substantially reduced. 


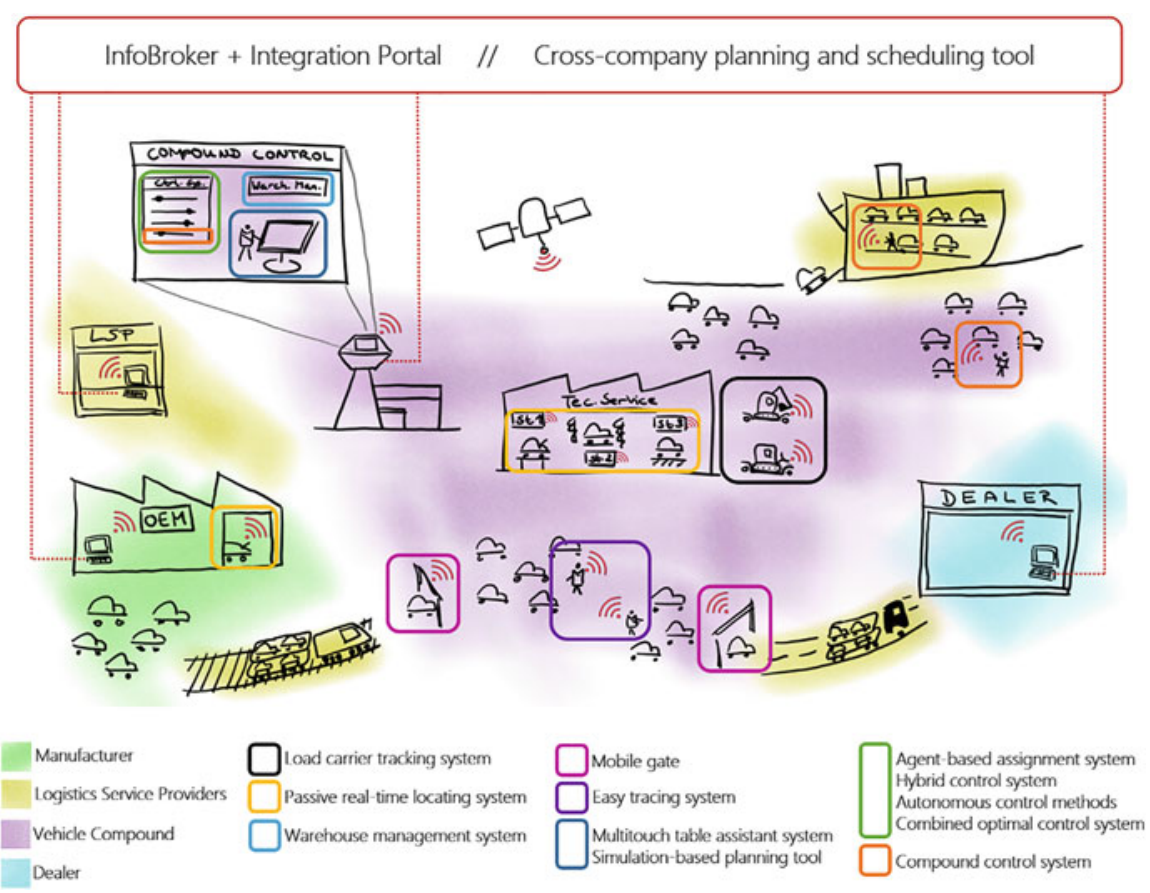

Fig. 7 Vision of a transparent finished vehicle distribution chain

In addition, the increased transparency allows better planning and control of logistics operations. If crucial data is missing, it cannot be considered for planning and control. If data is wrong or obsolete, planning or control will be erroneous as a result. In any case, planning and control will be sub-optimal.

\subsection{Vision 2: Adaptive Planning and Control of Vehicle Distribution Chains}

In addition to benefits from increased transparency, planning, and control processes themselves become better by using digital technologies. Automated planning and control processes supported by modern information processing technologies and based on suitable methods and algorithms can handle higher system complexity than previous methods primarily based on manual execution. Planning horizons can be extended further into the future, while planning cycles can be run more often. As a result, planning horizon and planning cycle times can be adapted to specific problems and situations.

Concerning the comprehensiveness of planning and control systems, two different developmental trajectories become possible: On the one hand, seamless 
information flow between different processes enables the collaborative and parallel planning of the different links and the integrated planning across the whole distribution chain. This global planning of the distribution chain, as exemplified by the cross-company planning and scheduling tool, allows a better overall planning solution than the isolated planning of each link with only rudimentary consideration of adjacent processes.

On the other hand, digital technologies allow delegation of previously centralized planning or control functions to individual elements of a system. Here, the concept of autonomous control allows, for instance, the decentralized assignment of parking spaces, or service times, based on negotiations of agents representing logistic objects, like vehicles, parking areas, and service stations. Such autonomous decision-making can relieve overall planning systems of unnecessary detail planning and make vehicle distribution systems more robust to better cope with high complexity and dynamics. Furthermore, hybrid approaches, such as the Hybrid control system for parking space allocation, allow combining the strengths of both autonomous control and central planning and control.

\subsection{Retrospective on the Research and Future Prospects}

The general course of research started with addressing more straightforward problems and developing basic but adequate solutions and proceeded towards more complex problems and solutions. For instance, the design of assistance systems started with the simpler Load carrier tracking system, using RFID, WLAN, and GPS technology to display locations of load carriers on the compound. The easy Tracing System, as an intermediate system, included a sensor box with an RFID reader, a Bluetooth module and a microcontroller, a mobile phone (with GPS, Wi$\mathrm{Fi}$, a GPRS module, and touch screen), a proximity sensor, an RFID antenna and batteries for energy supply. The most recent technical solution for locating vehicles, shuttles, and drivers on a vehicle compound combines a server, GPS positioning, an indoor positioning system, WLAN, and smartphones.

A similar course can be observed with regard to planning and control solutions. These started from a relatively simple, agent-based parking space allocation to cars, then added additional autonomous control solutions for service center operations. The most recent planning and control solutions integrate online simulation to evaluate medium-term planning alternatives or combine order assignment and shuttle routing using optimization methods. In order to achieve the best possible overall solution, these recent developments are not based on autonomous objects processing local information but rather on using ICT to provide accurate information on the current state of the terminal as a whole. In addition, increased emphasis is put on making the automatically computed data available to human planners via sophisticated interfaces for human-machine interaction.

Due to their particular importance as focal points within the distribution network and their sheer size, vehicle compounds have so far been the object of most attention 
and research activities. Consequently, most of the described systems and solutions address vehicle compound operations. This is particularly the case for assistance systems that allow higher automated or more efficient local processes. In addition, this may set a topic for future research activities to transfer assistance systems developed for vehicle compounds to use at other links of the distribution chain, such as the smaller storage yards of dealers. Several solutions are available for improving the planning and control across the distribution chain. Thus, future research can address the challenge to integrate local assistance systems with these more comprehensive solutions.

The newly developed systems have to be integrated into the existing, very heterogeneous IT infrastructures of the OEMs, LSP, vehicle compound operators, and dealers. The large variety of different and often mutually incompatible IT systems renders integration across the vehicle distribution chain very challenging. A first solution to this problem requires proper, standardized interfaces for data exchange. Often, a standardized interface for data exchange, such as the InfoBroker, may be sufficient. In other cases, closer functional integration may be required. Another possibility may be the usage of cloud computing systems.

The final motive of introducing digital systems is economic profit. Several potentials to leverage economic profit by reducing costs or increasing customer satisfaction have already been mentioned. In addition, increased digitalization offers potentials for new business models that may open up new revenue streams for the companies involved in vehicle distribution. For instance, the increased data available may allow fact-based evaluation and benchmarking of different transport routes and relations, allowing the long-term strategic optimization of vehicle distribution networks. Another business model is using transparency data to improve insurance and security systems. The tracking and tracing systems allow a factbased and automated allocation of responsibility for vehicle damage cases. This may reduce the high costs associated with damage classification and allocation. In addition, vehicle distributors may sell data to insurance companies, which allows the definition of insurance conditions better adapted to actual risks.

\section{Summary and Outlook}

BIBA and its project partners have developed a broad range of planning and control methods and assistance systems in the past years that span across the entire finished vehicle distribution chain and lend valuable support to the stakeholders of the distribution process. With minor adaptations, the majority of the methods and systems can become useful for different stakeholders and stages within the distribution network. Many methods and systems developed for use on vehicle compounds can handle operations of OEMs or dealers as well. Often, simplified versions should be sufficient for these stakeholders.

With continuing advances in mobile computation and location technologies, further progression of the developed systems is possible (Fig. 8). Current research 


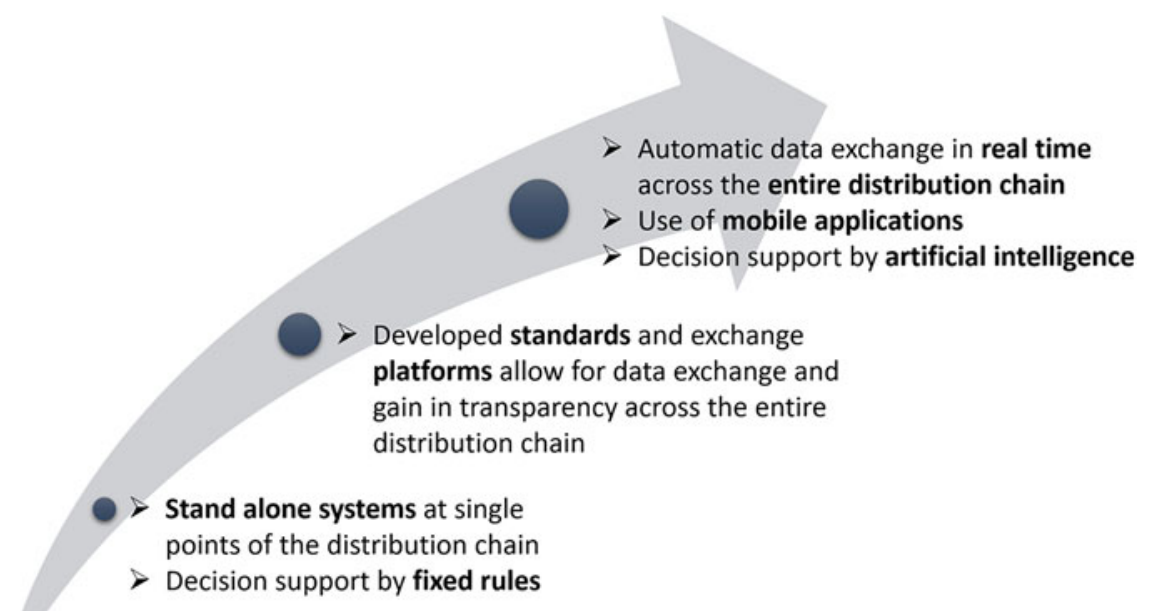

Fig. 8 Line of development in transparency and decision support systems within the finished vehicle distribution chain

shows that existing systems can be extended to additional groups of workers or further processes, such as stevedores or loading and unloading vehicles. Moreover, mobile applications offer significant potential for the digitalization of processes. This prevents, on the one hand, media disruptions and associated errors. On the other hand, data can be shared in real-time with adjacent processes and, if handy, with the entire distribution chain.

The advances in the field of artificial intelligence offer further potential for even better support. Assistance systems and fully automated systems can be improved for better recommendations based on more intelligent planning and control methods and decision rules that no longer need to be implemented manually. This opens up a new era of assistant and recommender systems, which can adapt to dynamic changes in vehicle distribution services.

Acknowledgments The research presented in this chapter was funded by German Research Foundation (DFG) as part of the Collaborative Research Center 637 "Autonomous Cooperating Logistic Processes-A Paradigm Shift and its Limitations," by the German Federal Ministry for Economic Affairs and Energy (BMWi) within the projects "ProKon-Use of innovative ICT technologies for process control in cargo and load carrier management at seaports," "LogPro_Logistical planning and control systems in RoRo and ConRo ports," "RAN-RFID-based Automotive Network," and "SaSch—Digital Services for Shaping Agile Supply Chains," and by the German Federal Ministry of Transport and Digital Infrastructure (BMVI) within the projects "ISABELLA-Automobile logistics in sea and inland ports: interactive and simulation-based operation planning, dynamic and context-based control of device and load movements" and "ISABELLA2-Automobile logistics in sea and inland ports: Integrated and user-oriented control of device and load movements through artificial intelligence and a virtual training application." 


\section{References}

Ambe, I.M., Badenhorst-Weiss, J.A.: Strategic supply chain framework for the automotive industry. African J Bus Manag. 4, 2110-2120 (2010)

Becker, T., Windt, K.: A comparative view on existing autonomous control approaches- observations from a simulation study. In: Hülsmann, M., Scholz-Reiter, B., Windt, K. (eds.) Autonomous Cooperation and Control in Logistics, pp. 275-289. Springer-Verlag, Berlin (2011)

Bleisteiner, T., Ramirez, A., Werthmann, D.: Die RAN-Erfassungsklassen. In: Transparenz in globalen Lieferketten der Automobilindustrie, pp. 185-203. Publicis Publishing, Erlangen (2014)

Böse, F.: Selbststeuerung in der Fahrzeuglogistik. Modellierung und Analyse selbststeuernder logistischer Prozesse in der Auftragsabwicklung von Automobilterminals. Gito Verlag, Berlin (2012)

Böse, F., Windt, K.: Autonomously controlled storage allocation on an automobile terminal. In: Hülsmann, M., Windt, K. (eds.) Understanding Autonomous Cooperation and Control in Logistics - the Impact on Management, Information and Communication and Material Flow, pp. 351-363. Springer, Berlin (2007)

Böse, F., Piotrowski, J., Scholz-Reiter, B.: Autonomously controlled storage management in vehicle logistics - applications of RFID and mobile computing systems. Int J RF Technol Res Appl. 1, 1-20 (2008)

Brandwein, D., Werthmann, D., Scholz-Reiter, B.: Infobroker und RFID-Technik in der multimodalen Fahrzeugdistribution. In: 18. Magdeburger Logistiktage. pp. 53-61. (2013)

Dias, J.C.Q., Calado, J.M.F., Mendonça, M.C.: The role of European «ro-ro» port terminals in the automotive supply chain management. J. Transp. Geogr. 18, 116-124 (2010)

Filz, B.: Kennzahlensystem für die Distribution: Modell für kleine und mittlere Unternehmen. TÜV Rheinland, Köln Verl (1989)

Finkenzeller, K.: RFID Handbuch. Grundlagen und praktische Anwendungen von Transpondern, kontaktlosen Chipkarten und NFC. Hanser, München (2015)

Fischer, T.: Multi-Agenten-Systeme im Fahrzeugumschlag - Agentenbasierte Planungsunterstützung für Seehafen-Automobilterminals. Deutscher Universitäts-Verlag, Wiesbaden (2004)

Genc, E., Duffie, N., Reinhart, G.: Event-based supply chain early warning system for an adaptive production control. Procedia CIRP. 19, 39-44 (2014)

Görges, M., Freitag, M.: Modeling autonomously controlled automobile terminal processes. In: Proceedings of the Hamburg International Conference of Logistics (HICL 2019). pp. 185-214. (2019a)

Görges, M., Freitag, M.: Dynamisierung von Planungsaufgaben auf Automobilterminals. Ind 40 Manag. 35, 23-26 (2019b)

GS1 EPCglobal: EPC Information Services (EPCIS) Standard. Release 1.2, Ratified, Sep. 2016. GS1 AISBL, Brussels, Belgium. https://www.gs1.org/sites/default/files/docs/epc/EPCISStandard-1.2-r-2016-09-29.pdf. (2016). Accessed 25 May 2021

Gudehus, T.: Logistik. Grundlagen, Strategien, Anwendungen. Springer, Heidelberg (2010)

Gudehus, T.: Logistik 1. Grundlagen, Verfahren und Strategien. Springer Vieweg, Berlin (2012)

Hammer, M., Champy, J.: Business reengineering : die Radikalkur für das Unternehmen. CampusVerl, Frankfurt/Main (2003)

Haubrich, H.: Optimierung der Fahrzeugdistribution mit Software der INFORM GmbH. In: Göpfert, I., Braun, D., Schulz, M. (eds.) Automobillogistik, pp. 287-304. Springer Gabler, Wiesbaden (2017)

Hermes, A.M.: Modellbasierte Bewertung von Potenzialen einer distributionsorientierten Programm- und Reihenfolgeplanung in der Automobilindustrie. Praxiswissen Service, Dortmund (2011)

Herold, L.: Kundenorientierte Prozesssteuerung in der Automobilindustrie. Deutscher Universitäts-Verlag, Wiesbaden (2005) 
Hoff-Hoffmeyer-Zlotnik, M., Schukraft, S., Werthmann, D., Oelker, S., Freitag, M.: Interactive planning and control for finished vehicle logistics. In: Jahn, C., Kersten, W., Ringle, C.M. (eds.) Digitalization in Maritime and Sustainable Logistics, pp. 77-93. epubli, Berlin (2017)

Hoff-Hoffmeyer-Zlotnik, M., Schukraft, S., Sprodowski, T., Freitag, M., Dunekacke, D., Zeitler, V., Görges, M.: Gestaltung von Mensch-Technik-Schnittstellen für die Digitalisierung von Planungs- und Steuerungsprozessen auf Automobilterminals. In: Freitag, M., Barthelmey, A. (eds.) Mensch-Technik-Interaktion in der digitalisierten Arbeitswelt, pp. 263-282. GITO mbH Verlag, Berlin (2020a)

Hoff-Hoffmeyer-Zlotnik, M., Sprodowski, T., Freitag, M.: Revisiting order assignment problems in a real-case vehicle compound scenario. In: Colloquium in Information Science and Technology, CIST. pp. 395-400. (2020b)

Hofmann-Wellenhof, B., Lichtenegger, H., Wasle, E.: GNNS - Global Navigation Satellite Systems. Springer, Wien, New York (2008)

Holweg, M., Miemczyk, J.: Logistics in the "three-day car" age - assessing the responsiveness of vehicle distribution logistics in the UK. Int. J. Phys. Distrib. Logist. Manag. 32, 829-850 (2002)

Hongler, M.O., Gallay, O., Hlsmann, M., Cordes, P., Colmorn, R.: Centralized versus decentralized controlA solvable stylized model in transportation. Phys A Stat Mech its Appl. 389, 4162-4171 (2010)

International Organization for Standardization. ISO/IEC 15417:2007. Information technology - Automatic identification and data capture techniques - Code 128 bar code symbology specification. Online: https://www.iso.org/standard/43896.html. (2007). Accessed 10 June 2021

International Organization for Standardization. SO/IEC 15459-1: 2014. Information technology - Automatic identification and data capture techniques - Unique identification - Part 1: Individual transport units. Online: https://www.iso.org/standard/54779.html. (2014). Accessed 10 June 2021

International Organization for Standardization. ISO/IEC 18000-63: 2015: Information technology - Radio frequency identification for item management - Part 63: Parameters for air interface communications at $860 \mathrm{MHz}$ to $960 \mathrm{MHz}$ Type C. Online: https://www.iso.org/standard/ 63675.html. (2015). Accessed 10 June 2021

Jathe, N., Lütjen, M., Freitag, M.: Indoor positioning in car parks by using Wi-fi round-trip-time to support finished vehicle logistics on port terminals. IFAC-PapersOnLine. 52, 857-862 (2019)

Jesse, R., Rosenbaum, O.: Barcode: Theorie, Lexikon, Software, 1. Aufl. Verl Technik. Berlin. (2000)

Kagermann, H., Wahlster, W., Helbig, J.: Umsetzungsempfehlungen fuer das Zukunftsprojekt Industrie 4.0. acatech. Deutsche Akademie der Technikwissenschaften e.V, München (2013)

Kaplan, E.D., Hegarty, C.J.: Understanding GPS/GNSS. Principles and Applications. Arttech House, Boston, MA (2017)

Kischporski, M.: EDI - Digitalisierung und IT-Wertbeitrag konkret umgesetzt. Springer Gabler, Wiesbaden (2017)

Klug, F.: Logistikmanagement in der Automobilindustrie - Grundlagen der Logistik im Automobilbau. Springer Vieweg, Berlin (2018)

Lampe, W: nachhaltig bewegen. Nachhaltigkeitsbericht 2012. Bremen. (2012)

Lödding, H.: Handbook of Manufacturing Control: Fundamentals, Description, Configuration. Springer, Berlin (2011)

LogDynamics. Bremen Research Cluster for Dynamics in Logistics. http://www.logdynamics.de/ logdynamics.html?\&L=1. (2021)

Monostori, J.: Supply chains robustness: challenges and opportunities. Procedia CIRP. 67, 110-115 (2018)

Mori, S., Suen, C.Y., Yamamoto, K.: Historical review of OCR Research and Development. Proc. IEEE. 80, 1029-1058 (1992) 
Mrugala, D., Ruthenbeck, C., Scholz-Reiter, B., Lang, W.: Smart jacket as a computing system for automobile warehouse logistics. In: European Conference \& Exhibition on Integration Issues of Miniaturized Systems. Brüssel, pp. 492-495. (2008)

Musa, A., Gunasekaran, A., Yusuf, Y.: Supply chain product visibility: methods, systems and impacts. Expert Syst. Appl. 41, 176-194 (2014)

Nait-Sidi-Moh, A., Bakhouya, M., Gaber, J., Wack, M.: Geopositioning and Mobility. ISTE, London (2013)

Negri, E., Fumagalli, L., Macchi, M.: A review of the roles of digital twin in CPS-based production systems. Procedia Manuf. 11, 939-948 (2017)

Pfohl, H.-C.: Logistiksysteme. Betriebswirtschaftliche Grundlagen, 8th edn. Springer, Berlin (2010)

Pham, Q.V., Fang, F., Ha, V.N., Piran, M.J., Le, M., Le, L.B., Ding, Z.: A survey of multi-access edge computing in $5 \mathrm{G}$ and beyond: fundamentals, technology integration, and state-of-the-art. IEEE Access. 8, 116974-117017 (2020)

Power, D.J.: Decision Support Systems. Concepts and Resources for Managers. Quorum Books, Westport (2002)

Rech, J.: Wireless LANs. 802.11-WLAN-Technologie und praktische Umsetzung im Detail. Heise, Hannover (2012)

Ross, D.F.: Distribution Planning and Control: Managing in the Era of Supply Chain Managemen. Springer, Boston, MA (2015)

Ruthenbeck, C., Lappe, D., Lampe, W.: Informationsmanagement in der Automobillogistik. Ind Manag. 26, 9-13 (2010)

Schenk, L.: ActiveBarcode. Barcode Software seit 1994. https://www.activebarcode.de/ (2021)

Schenk, A., Clausen, U.: Creating transparency in the finished vehicles transportation process through the implementation of a real-time decision support system. IEEE Int Conf Ind Eng Eng Manag. 12, 1017-1021 (2020)

Scholz-Reiter, B., Meinecke, C.: Planungsmethode für die unternehmensübergreifende Auftragsabwicklung. Ind Manag. 26, 39-42 (2010)

Scholz-Reiter, B., Meinecke, C.: Nutzen von Informationstransparenz im Seehafenterminal. Prod. Manag. 16, 56-58 (2011)

Scholz-Reiter, B., Böse, F., Dizdar, C., Windt, K.: Transportorientierte Reihenfolgeplanung Verbesserte Abstimmung zwischen Produktion und Distribution. PPS Manag. 13, 15-17 (2008)

Scholz-Reiter, B., Böse, F., Teucke, M., Virnich, A.: Ladungsträgermanagement auf RoRoTerminals. Ind Manag. 25, 25-28 (2009a)

Scholz-Reiter, B., Frazzon, E.M., Makuschewitz, T.: Integration von Produktions- und Transportsystemen entlang globaler supply chains. Ind Manag. 25, 31-34 (2009b)

Scholz-Reiter B., Isenberg M. A., Virnich, A., Özsahin, M. E.: Innovative load carrier management solution for seaport terminals - based on positioning, identification and communication technologies. In: Proceedings of the 5th international Congress on Logistics and SCM Systems (ICLS 2009). pp. 638-644. (2009c)

Scholz-Reiter, B., Meinecke, C., Ruthenbeck, C.: Development of a cross-company planning and scheduling method for the supply chain management of RoRo and ConRo-Ports. In: 1st International Conference on Logistics and Transport. pp. 1-15. (2009d)

Scholz-Reiter, B., Isenberg, M. A., Virnich, A., Özsahin, M. E.: Automatic load carrier management on RoRo terminals. In: 2010 Annual Conference of the International Association of Maritime Economists. pp. 2-19. (2010a)

Scholz-Reiter, B., Özsahin, M. E., Schweizer, A., Isenberg, M. A.: Combined information and communication technologies for location and status transprancy on Ro-Ro terminal. In: 12th Int. Conference on Harbor, Maritime and Multimodal Logistics Modeling and Simulation, HMS 2010. pp. 127-132. (2010b)

Scholz-Reiter, B., Lappe, D., Toonen, C., Ruthenbeck, C.: Development of a hybrid control approach for automotive logistics based on close to real-time information management. Int J Syst Appl Eng Dev. 5, 545-552 (2011) 
Scholz-Reiter, B., Lappe, D., Ruthenbeck, C., Toonen, C.: Hybride Steuerung logistischer Prozesse. wt Werkstattstech. 102, 240-245 (2012a)

Scholz-Reiter, B., Werthmann, D., Lappe, D., Otterstedt, N.: Ortungsgestützte Steuerung von Qualitätssicherungsprozessen. Ind Manag. 28, 22-26 (2012b)

Schuh, G.: Distributionslogistik. In: Schuh, G., Stich, V. (eds.) Logistikmanagement. Handbuch Produktion und Management 6. Springer, Berlin (2013)

Schukraft, S., Oelker, S., Werthmann, D., Freitag, M., Görges, M., Gencer, E., Malek, A.: Interaktive Planung und Steuerung für den Automobilumschlag. Ind 40 Manag. 33, 11-14 (2018)

Seeck, S.: Erfolgsfaktor Logistik. Klassische Fehler erkennen und vermeiden. Gabler, Wiesbaden (2010)

Servos, N., Liu, X., Teucke, M., Freitag, M.: Travel time prediction in a multimodal freight transport relation using machine learning algorithms. Logistics. 4, 1-22 (2020)

Strang, T., Schubert, F., Oberweis, R.: Lokalisierungsverfahren. Deutsches Zentrum für Luft- und Raumfahrt (DLR), Oberpfaffenhofen. (2008)

Teucke, M., Broda, E., Börold, A., Freitag, M.: Using sensor-based quality data in automotive supply chains. Mach. Des. 6, 1-22 (2018)

Tröger, R.: Supply Chain Event Management - Bedarf, Systemarchitektur und Nutzen aus Perspektive fokaler Unternehmen der. Universität Leipzig, Modeindustrie (2014)

Werthmann, D., Lappe, D., Otterstedt, N., Scholz-Reiter, B.: Ortungsgestütztes Produktionsleitsystem für die Nacharbeit bei Automobilherstellern. wt Werkstattstech. 102, 114-119 (2012)

Werthmann, D., Brandwein, D., Ruthenbeck, C., Scholz-Reiter, B.: Standardized information exchange in automotive distribution processes. In: 2013 IFAC Conference on Manufacturing Modelling, Management and Control. pp. 700-705. (2013)

Werthmann, D., Bender, M., Engelhardt, P., Winkler, M., Parlings, M., Reinhardt, S.: Von der Idee zur Umsetzung - ein Leitfaden. In: Lepratti, R., Lamparter, S., Schröder, R. (eds.) Transparenz in globalen Lieferketten der Automobilindustrie, pp. 60-116. Publicis Publishing, Erlangen (2014)

Werthmann, D., Brandwein, D., Ruthenbeck, C., Scholz-Reiter, B., Freitag, M.: Towards a standardised information exchange within finished vehicle logistics based on RFID and EPCIS. Int. J. Prod. Res. 55, 4136-4152 (2016)

Windt, K, Becker, T, Kolev, I: A comparison of the logistics performance of autonomous control methods in production logistics. In: Proceedings of the 43rd CIRP International Conference on Manufacturing Systems. Vienna, pp. 576-583. (2010)

Zekavat, S.A., Buehrer, R.: Handbook of Position Location. IEEE Press, Piscataway (2019)

Open Access This chapter is licensed under the terms of the Creative Commons Attribution 4.0 International License (http://creativecommons.org/licenses/by/4.0/), which permits use, sharing, adaptation, distribution and reproduction in any medium or format, as long as you give appropriate credit to the original author(s) and the source, provide a link to the Creative Commons license and indicate if changes were made.

The images or other third party material in this chapter are included in the chapter's Creative Commons license, unless indicated otherwise in a credit line to the material. If material is not included in the chapter's Creative Commons license and your intended use is not permitted by statutory regulation or exceeds the permitted use, you will need to obtain permission directly from the copyright holder. 